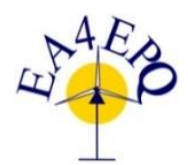

International Conference on Renewable Energies and Power Quality (ICREPQ'17)

Malaga (Spain), $4^{\text {th }}$ to $6^{\text {th }}$ April, 2017

Renewable Energy and Paver Qualily. Sournal (RE\&PQJ)

ISSN 2172-038 X, No.15 April 2017

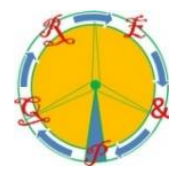

\title{
An On-board Energy Storage System for Catenary Free Operation of a Tram
}

\author{
H. M. Al-Ezee ${ }^{1}$, S. Tennakoon ${ }^{1}$, I. Taylor ${ }^{1}$, D. Scheidecker ${ }^{2}$ and J. Schweickart ${ }^{2}$ \\ ${ }^{1}$ School of Creative Arts and Engineering \\ Staffordshire University \\ College Road - Stoke on Trent, ST4 2DE \\ United Kingdom \\ Tel: +44 (0) 1782294861 \\ E-mail: h.al-ezee@staffs.ac.uk \\ ${ }^{2}$ NewTL S.A.S. \\ NTL - CS 79207 - 67129 MOLSHEIM CEDEX \\ France \\ Tel: +33 (0) 368710354 \\ Email: daniel.scheidecker@translohr.com
}

\begin{abstract}
.
Modern cities require zero emissions, silent, and energy efficient transport solutions that have low or no visual impact on the environment. On-board energy storage systems have a significant role in providing the required energy during catenary free operation of trams and in recovering regenerated energy from braking. The energy consumption of a commercial tram for a total journey length of $13 \mathrm{~km}$ has been simulated for proper sizing of the onboard energy storage. The energy storage system is recharged during stops at stations through wayside power delivery technologies and by the use of available braking energy. Due to this, the on-board energy storage system is required to provide a catenary free gap of about $1 \mathrm{~km}$. A power conversion system, Bi-Directional DC-DC converter, and a charge/discharge energy management system are required for the realisation of catenary free system.
\end{abstract}

\section{Key words}

Energy Storage, Catenary Free Operation, DC-DC Converter, Energy Management System.

\section{Nomenclature}

$\begin{array}{cl}P_{\text {tram }} & \text { Power drawn by a tram } \\ V_{d c} & \text { DC-link Voltage } \\ F_{t} & \text { Total traction force } \\ v & \text { Tram Speed }(\mathrm{m} / \mathrm{s}) \\ \eta_{e m} & \text { Electrical motor efficiency } \\ \eta_{i n v} & \text { Inverter efficiency } \\ \eta_{\text {mech }} & \text { Mechanical efficiency } \\ T_{w} & \text { Wheel Torque } \\ R_{w h e e l} & \text { Radius of the wheel } \\ \tau & \text { Transmission ratio } \\ F_{R} & \text { Train resistance force }(\mathrm{N}) \\ m & \text { Tram mass }(\mathrm{kg})\end{array}$

$A$

$B$

C
Coefficient of the Davis equation (N)

Coefficient of the Davis equation ( $\mathrm{N} \mathrm{s} / \mathrm{m})$

Coefficient of the Davis equation $\left(\mathrm{N} \mathrm{s}^{2} / \mathrm{m}^{2}\right)$

\section{Introduction}

The removal of overhead electrical installations (catenaries) is a major consideration of light railway industries. This is driven by continuous focus on environmental concerns and reduction of energy consumption. Realisation of catenary free systems provides a reduction in both the level of visual pollution and the power consumption pattern.

One vital power electronic equipment necessary for the realisation of such a system is a Bi-Directional DC to DC converter for interfacing the energy storage (battery) to the drive system. The converter and the energy storage system are housed on-board the tram so that the vehicle can be propelled from the energy stored when the external power supply is not available.

An energy management system is required to propel the vehicle in the most energy efficient manner dependent upon the level of energy stored, the load profile and the auxiliary energy requirements; and to ensure most efficient charging of the energy storage system when the power is available from the wayside equipment.

An investigation was carried out to determine the energy storage system on-board a tram for catenary free operation. Energy flow analysis was performed for a specified drive cycle to evaluate the total energy consumption of a commercial tram for proper sizing of the on-board energy storage. A mathematical model of the physical traction system was implemented by using Matlab/Simulink. 


\section{Power Delivery Technologies}

\section{A. On-board Energy storage options}

Batteries: A battery is a collection of electro-chemical cells either parallel or series connected to obtain a required power capability. Contenders are Li-ion and Sodium Nickel. Batteries have high energy density; however, they have low power density. The battery has constant energy density for the particular choice of active materials. Batteries can be used for catenary free operation to power the tram for substantial distances of a few kilometres. The key parameters of a battery that need to be considered in a railway system are: Lifetime, operating temperature, number of cycles, rate of charging/discharging (c-rate), the depth of discharge (DOD), weight, cost and safety [1].

Super capacitors: Super capacitors have high power density quick charging and discharging but poor energy density, compared to batteries. Super capacitors can be used for recovering braking energy. Energy saving is possible depending on the amount of installed super capacitors and the mission profile. However the energy density is lower and hence only sections of less than 500m are possible [2].

Fuel Cells: This solution is not mature enough for railway applications. The network to provide hydrogen is still to develop and the costs are still very high compared to other solutions [1].

Flywheels: This solution allows quick charging. However, the cost is high, have moving parts, safety and reliability need to be improved and the technology is technically not yet ready for commercial operation [3].

\section{B. Power delivery Technologies}

WiPoST by NewTL [1]: This solution replaces the overhead electrical installations (catenaries). Current injection points are located along the route so that they come in contact with the conductor strip installed on the roof of the tramway as it passes. In this way street lighting and the fixed equipment of the WiPoST system can be combined. The posts are located along the trackway, in and on the approaches to stations and in the areas where the tram accelerates. On the rest of the route, the tram travels using the on-board energy storage.

Inductive Power transfer: Bombardier has developed PRIMOVE technology [4]. The advantage is to operate catenary free over varying distances through contactless power transfer buried in the ground.

Opportunity charging: This technique is based on fast wayside energy system transfer [4]. The SITRAS SES help the power supply system to avoid short periods of electrical failure and also reduce the effect of the voltage drop on many trams consuming power simultaneously.

Embedded Systems: ALSTOM and SPIE ENERTRANS developed APS as a service-proven power system for tramways which supplies electricity through a third rail at ground level and eliminates the need for catenaries [4]. ALSTOM developed SRS which is a ground based static charging for trams with on-board energy storage.

\section{Electrical Drive System}

\section{A. System Description}

A typical tram system drive transforms electrical energy from the traction power supply system into kinetic and potential energy. The conversion can be divided into several stages as shown in Figure 1; AC voltage $\left(\mathrm{V}_{\mathrm{AC}}\right)$ is rectified within the trackside substation to produce a DC voltage $\left(\mathrm{V}_{\mathrm{DC}}\right)$. The $\mathrm{DC}$ voltage is fed via the catenary to the traction drive that consists of a 3-phase power inverter, an AC motor, and mechanical transmission. The on-board power inverter converts DC voltage supply into 3-phase variable frequency variable voltage supply. The power inverter consists of six switches (IGBTs with anti-parallel diodes) which enables bi-directional power flow between the DC link and AC motor. Electrical power delivered to the traction motors achieves the motor torque. The final stage of the drive is the mechanical transmission (gearbox and wheel set). The mechanical energy delivered by the $\mathrm{AC}$ motors is converted into kinetic and potential energy.

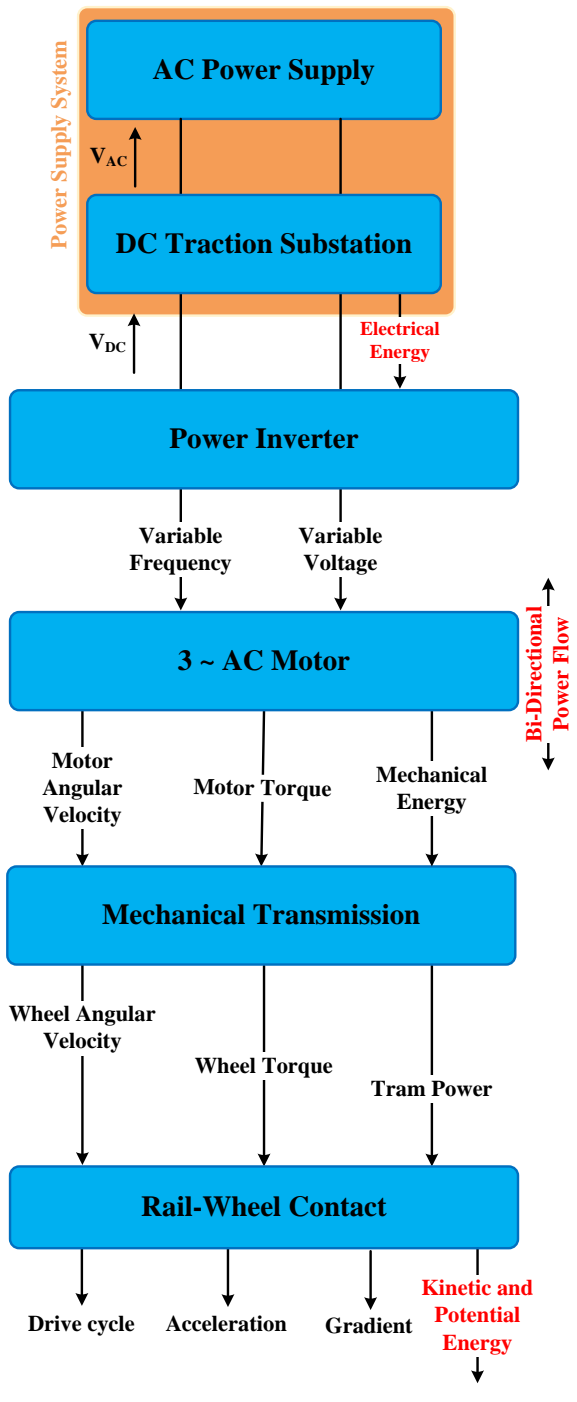

Figure 1 Electrical drive configuration of a tram

An energy flow diagram for a conventional tram is shown in Figure 2, where the tram energy is used to overcome tractive resistive forces. Energy is also dissipated in braking, through other mechanisms including driveline losses and to power auxiliary loads [5]. 


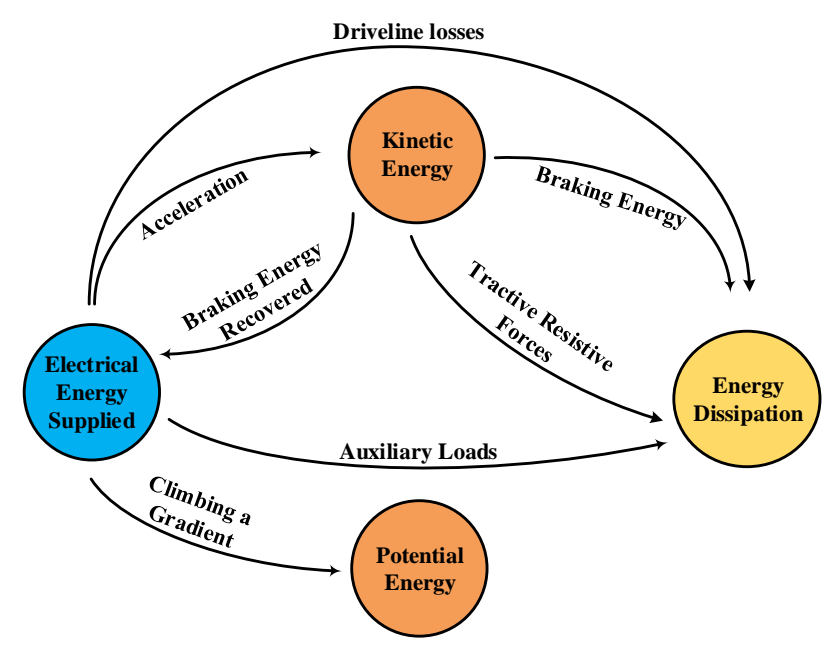

Figure 2 Energy consumption in a Tram

In a typical DC tram system, regeneration of braking energy back to local distribution network is not possible as the DC traction substations are not bi-directional in power flow [6]. However, when the distance between tram vehicles is significant, the recovery of braking energy is possible if, at the same time, a train is accelerating and another is braking [7]. As a result the recovery of kinetic energy during braking subjects to unpredictable traffic conditions [8]. Implementation of energy storage system on-board a tram allow the optimised recovery of braking energy and catenary free operation. Figure 3 shows the schematic which allows energy storage to be implemented on-board a tram. The braking resistor is installed in case the energy storage is unable to absorb braking energy. The energy flow to and from the energy storage is governed by controlling the DC-DC converter based on the drivers' traction/braking commands. Auxiliary loads are additional loads which only consume power, these include HVAC, lightings, doors, control and monitoring systems.

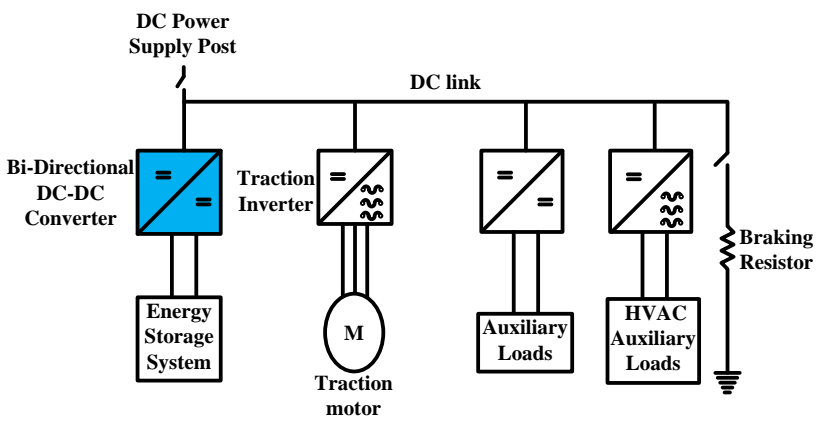

Figure 3 On-board arrangement of energy storage system

\section{B. System modelling}

A simulation model of the tram system shown in Figure 1 was used to evaluate the total energy consumption for the purpose of proper sizing of the on-board energy storage system. The simulation model describes implementation of the mathematical model of the physical system using Matlab/Simulink. The behaviour of a commercial tram was simulated over the drive cycle shown in Figure 4 provided by NewTL Co. The tramway consists of current injection points at station stops, which are frequently spaced with a total of 30 stops along the $13 \mathrm{~km}$ route.

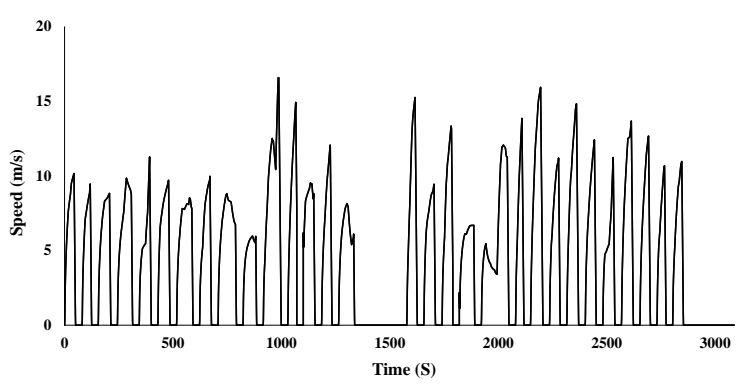

Figure 4 Tram Drive Cycle (Curtsey of NewTL Co.)

An adopted inverse modelling technique [9] was used. The rail-wheel contact subsystem shown in Figure 1 represent the total tractive effort (resistive forces). The subsystem takes the tram system drive cycle, acceleration profile (shown in Figure 5), and gradient profile to determine the tram power and the total tractive effort.

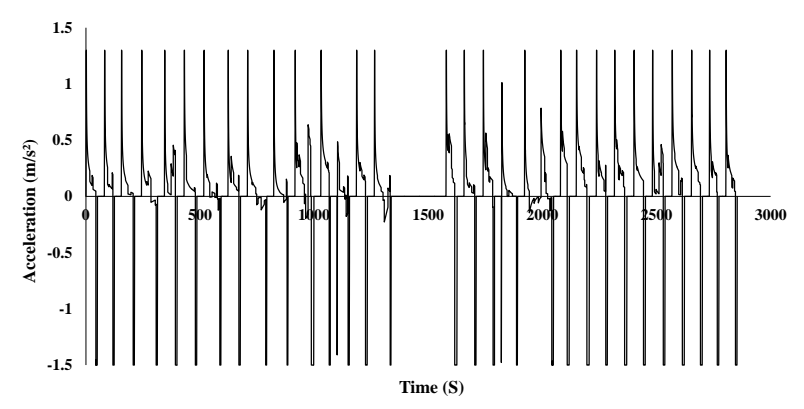

Figure 5 Tram acceleration profile

The tram power depends on the drive cycle and total tractive effort and is given by:

$$
P_{\text {tram }}= \begin{cases}\frac{F_{t} v}{\eta_{e l} \eta_{\text {mech }}}, & F_{t}>0 \\ F_{t} v \eta_{e l} \eta_{\text {mech }}, & F_{t}<0\end{cases}
$$

Where

$$
\eta_{e l}=\eta_{e m} \eta_{i n v}
$$

The wheel torque of the rail-wheel contact is given by:

$$
T_{w}=\frac{F_{t} R_{w h e e l}}{\tau}
$$

The tram power is used to overcome the total tractive effort $\left(F_{t}\right)$ required to drive the tram. The total tractive effort is given by:

$$
\begin{gathered}
F_{t}=\text { Tractive resistance }+ \text { gradient force }+ \text { inertia force } \\
\qquad F_{t}=F_{R}+m g \sin \theta+m^{*} a
\end{gathered}
$$

The tractive resistance, $F_{R}$, is known as Davis equation, can be written as follows:

$$
F_{R}=A+B v+C v^{2}
$$

The coefficients $A, B$, and $C$ are often experimentally determined [9]. Coefficients $A$ and $B$ of the Davis equation include the resistive forces that are related to the mass of the tram, one of the reasons for reducing the weight of tram vehicles. At high speeds, the $C V^{2}$ term, which is related to the aerodynamic resistance, becomes dominant and is the reason for the high installed power of high-speed trains [10]. The tram power over the drive cycle is shown in Figure 6 . The tram power is required to enable the tram to overcome the tractive resistance, inertia force and gradient 
force. The amount of energy consumed overcoming resistive forces over the drive cycle is about $13.9 \mathrm{kWh}$.

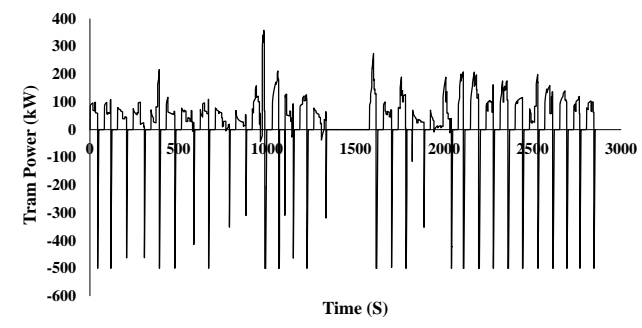

Figure 6 Tram Power

During braking, the tram has large braking power peaks over the whole journey. This is due to the tram braking at certain driving speeds that regenerates large amount of power. The available amount of energy from braking over the drive cycle is $6.8 \mathrm{kWh}$. The auxiliary load for the tram is assumed to be constant; measurements have indicated that the average auxiliary load is $51 \mathrm{~kW}$. Taking into account, the efficiency of power inverter, on-board motor, and mechanical transmission is 0.95 , an energy amount of about $55.2 \mathrm{kWh}$ over the drive cycle is required for the total journey without recharge of the on-board energy storage and the use of energy available from braking.

Table 1 Energy distribution over the drive cycle

\begin{tabular}{lc}
\hline & Energy (kW.hr) \\
\hline Total resistive forces & 13.9 \\
Auxiliary Loads & 40.4 \\
Braking Energy & 6.8 \\
Driveline losses & 0.9 \\
\hline \hline
\end{tabular}

Figure 7 shows the drive cycle between station (1) and station (2), where different phases for the source of energy provided to the tram are explained.

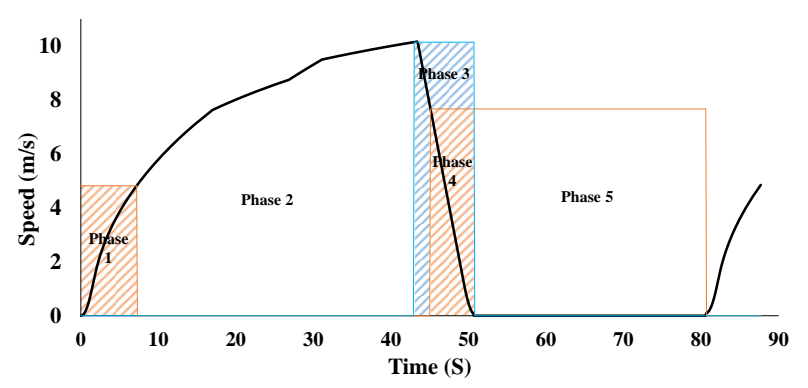

Figure 7 Drive cycle between station 1 and station 2 stops

The energy requested during acceleration phase is supplied initially, phase 1 in Figure 7, by power supply posts (current injection points) available at station stops for about $5 \mathrm{~s}$. The energy requested during catenary free gap, phase 2 in Figure 7 , is supplied by the on-board energy storage system. During braking phase, phase 3 in Figure 7, the energy storage system is recharged by the energy regenerated from the electrical drive. As the tram approaches to the next station stop, phase 4 in Figure 7, in addition to the energy regenerated from braking the on-board energy storage system is recharged through the power supply posts for about 5s. At the station stop, phase 5 in Figure 7, on-board energy storage system is recharged through the power supply posts for about $30 \mathrm{~s}$. The tram energy consumption pattern is shown in Figure 8. By analysing the full speed profile (Figure 4), the peak energy calculated was about 5.5 $\mathrm{kWh}$ during the total journey with recharge of the on-board energy storage as shown in Figure 7. This is $10 \%$ only of the total energy required for the journey which is 55.2 $\mathrm{kWh}$. Therefore, the required duty can be met by a smaller energy storage system.

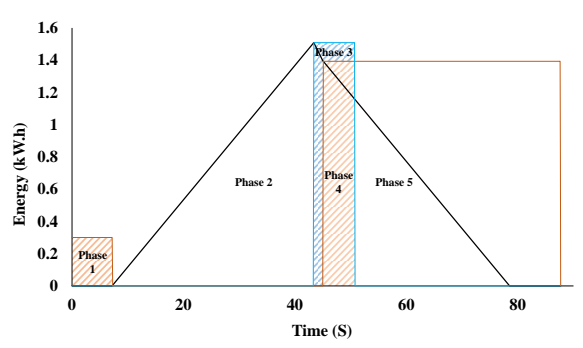

Figure 8 Energy consumption with recharge of on-board energy storage between station 1 and station 2 stops

\section{Evaluation of the Bi-Directional DC-DC Converter}

The Bi-directional DC-DC converter topology shown in Figure 9 represents one arm of a six pulse bridge converter for continuous charging power of $150 \mathrm{~kW}$. As depicted in the figure, the DC link is connected to the energy storage system through the Bi-directional DC-DC converter.

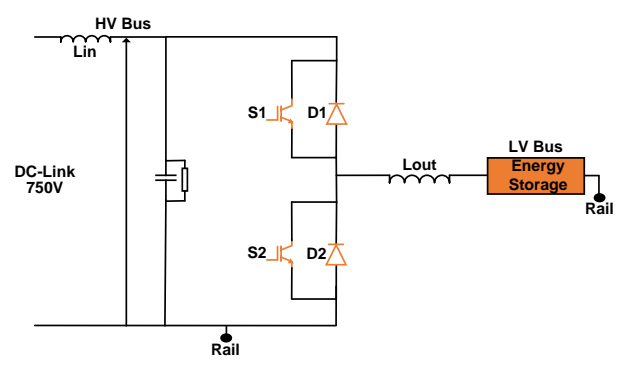

Figure 9 Bi-Directional DC-DC converter topology

The Bi-Directional DC-DC converter schematic shown in Figure 9 was implemented by using Matlab/Simulink software package. The simulation system model was used to evaluate the electrical power transformed from the DClink to the on-board energy storage system and vice versa.

The simulated Bi-Directional DC-DC converter parameters are given in Table 2.

\begin{tabular}{lcc} 
Table 2 Characteristics of Bi-Directional DC-DC converter \\
\hline \hline High voltage side (DC-link) & {$[\mathrm{V}]$} & 750 \\
Low Voltage side (energy storage) & {$[\mathrm{V}]$} & 375 \\
Average output power & {$[\mathrm{KW}]$} & 150 \\
Switching Frequency & {$[\mathrm{Hz}]$} & 1000 \\
DC link side inductance, Lin & {$[\mathrm{mH}]$} & 0.5 \\
Energy storage side inductance, Lout & {$[\mathrm{mH}]$} & 3 \\
DC link capacitance & {$[\mathrm{mF}]$} & 3 \\
DC link resistance & {$[\Omega]$} & 1000 \\
Duty ratio & & 0.5 \\
\hline
\end{tabular}

The on-board energy storage system was simulated as an $\mathrm{RC}$ equivalent circuit of a battery model. The parameters of $R$ and $C$ are $180 \mathrm{~m} \Omega$ and 211Farad consequently. During the charging phase of the on-board energy storage system, the nominal value of the high voltage side is $750 \mathrm{~V}$. The Bi-directional DC-DC converter works in buck mode to control the recharge current of the energy storage system. The waveforms of DC link and energy storage sides' inductor currents, and the low voltage side are depicted in Figure 10. 

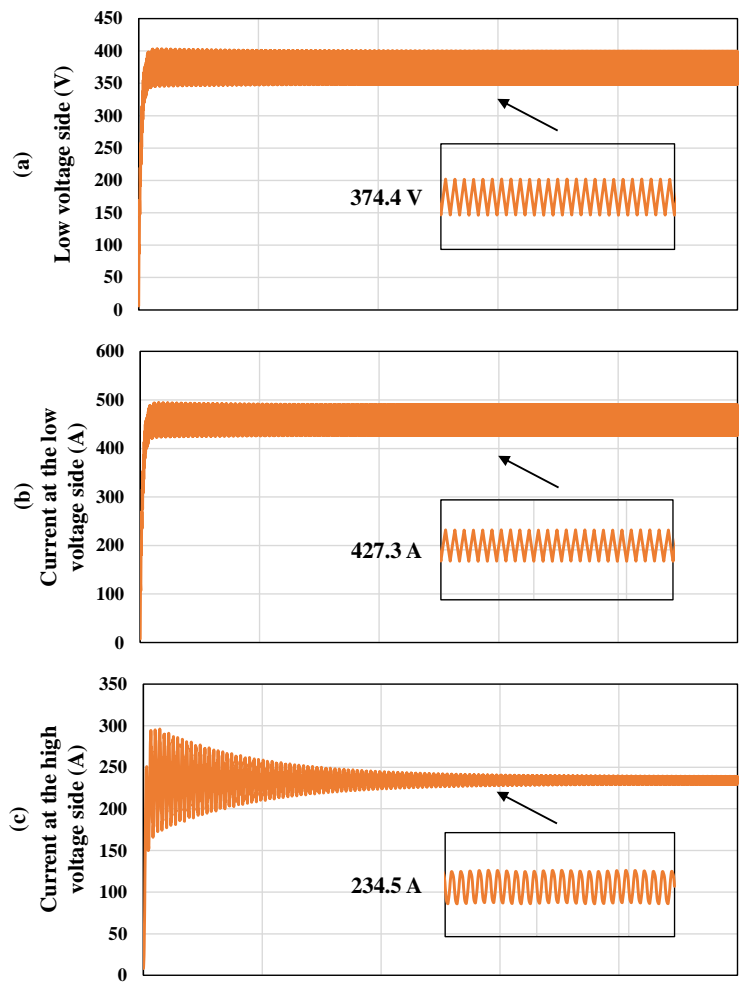

Figure 10 Buck mode simulation waveforms of (a) Low voltage side, (b) Inductor current at the low voltage side, (c) Inductor current at the high voltage side.

During the discharging phase of the on-board energy storage system, the value of the low voltage side is $375 \mathrm{~V}$. The Bi-directional DC-DC converter works in boost mode in order to regulate the voltage at the DC link. The waveforms of DC link and energy storage sides' inductor currents, and the high voltage side are depicted in Figure 11.
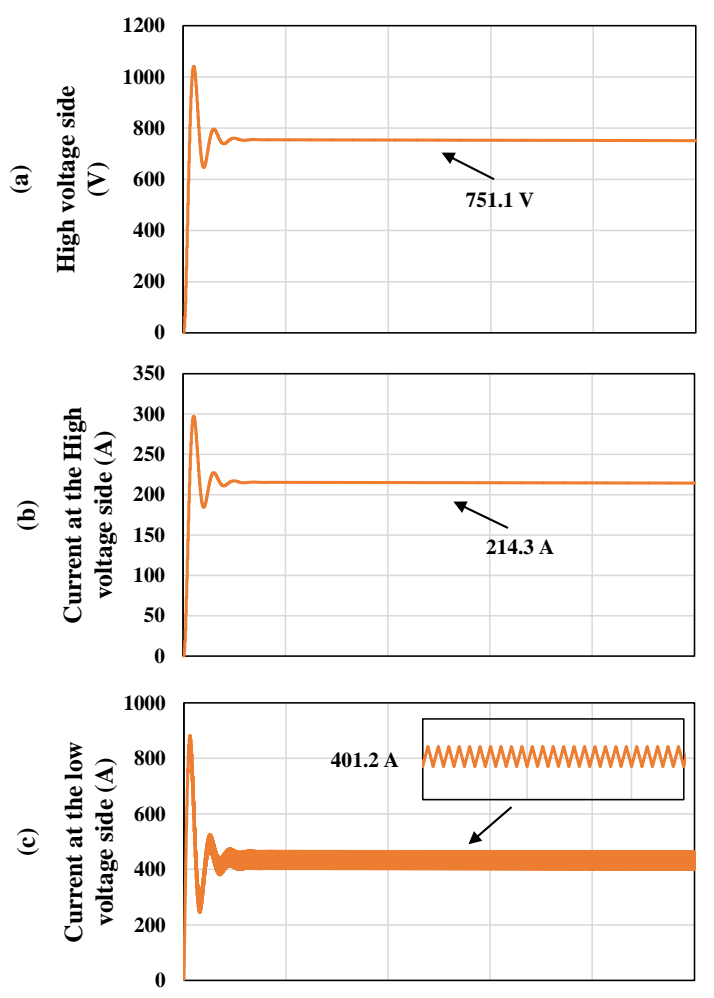

Figure 11 Boost mode simulation waveforms of (a) High voltage side, (b) Inductor current at the high voltage side, (c) Inductor current at the low voltage side.

\section{Conclusions}

A variety of energy storage solutions with way-side power delivery technologies have been explained. An analysis was performed to determine the energy which needs to be delivered for a proper sizing of on-board energy storage. Modelling of a particular tram system found that about $55.2 \mathrm{kWh}$ is required to be delivered to cover a distance of $13 \mathrm{~km}$ without recharge. It was also found, with recharge, an energy storage system capable of providing about 5.5 $\mathrm{kWh}$ capacity is sufficient to meet the duty. A BiDirectional DC-DC converter needs to be designed to enable energy storage and recovery of braking energy. An efficient energy management system is required to manage the energy consumption during catenary free operation.

\section{References}

[1] H. Al-Ezee, S. B. Tennakoon, I. Taylor, and D. Scheidecker, "Aspects of catenary free operation of DC traction systems," in 50th International Universities Power Engineering Conference (UPEC), 2015, vol. 2015-Novem, pp. 1-5.

W. Lhomme, P. Delarue, P. Barrade, A. Bouscayrol, and A. Rufer, "Design and control of a supercapacitor storage system for traction applications," Fourtieth IAS Annu. Meet. Conf. Rec. Ind. Appl. Conf. 2005., vol. 3, pp. 2013-2020.

[3] M. L. Sough, D. Depernet, F. Dubas, G. Gaultier, B. Boualem, and C. Espanet, "High frequency PMSM and inverter losses analysis-application to flywheel system on real cycle operation," in IEEE Vehicle Power and Propulsion Conference, 2011, pp. 1-5.

[4] W. Jeong, S. Kwon, D. Park, and W. S. Jung, "Efficient Energy Management For Onboard Battery-Driven Light Railway Vehicle," 9th World Congr. Railw. Res., 2011.

M. Chymera, "Analyzing the potential of energy storage on electrified transit systems," in 8th World Congress of Railway Research - WCRR, 2008.

F. Ciccarelli, D. Iannuzzi, and P. Tricoli, "Control of metro-trains equipped with onboard supercapacitors for energy saving and reduction of power peak demand," Transp. Res. Part C Emerg. Technol., vol. 24, pp. 36-49, Oct. 2012.

R. D. White, "Part 2 DC railway electrification supply system," in IET Professional Development Course on Electric Traction Systems, 2012, pp. 165-188.

B. Mellitt, "Simulation study of DC transit systems with inverting substations," Electr. Power Appl. IEE Proc. B, vol. 131, no. 2, pp. 38-50, 1984.

M. Z. Chymera, A. C. Renfrew, M. Barnes, and J. Holden, "Modeling Electrified Transit Systems," IEEE Trans. Veh. Technol., vol. 59, no. 6, pp. 2748-2756, Jul. 2010.

[10] B. P. Rochard and F. Schmid, "A review of methods to measure and calculate train resistances," Proc. Inst. Mech. Eng. Part F J. Rail Rapid Transit, vol. 214, no. 4, pp. 185-199, Jan. 2000. 